\title{
Noise in the outpatient operating room
}

\author{
Min Liu, Chen Yi, Fei Yin, Yu Dai \\ Department of Operation, The Central Hospital of Wuhan \& Affiliated Hospital of Tongji Medical College of Huazhong University of Science and \\ Technology, Wuhan 430000, China \\ Contributions: (I) Conception and design: M Liu; (II) Administrative support: None; (III) Provision of study materials or patients: M Liu, C Yi; (IV) \\ Collection and assembly of data: C Yi; (V) Data analysis and interpretation: All authors; (VI) Manuscript writing: All authors; (VII) Final approval of \\ manuscript: All authors. \\ Correspondence to: Liu Min; Yi Chen. Department of Operation, The Central Hospital of Wuhan \& Affiliated Hospital of Tongji Medical College of \\ Huazhong University of Science and Technology, Wuhan 430000, China. Email: 11096257@qq.com; 165564104@qq.com.
}

\begin{abstract}
Background Noise exposure in hospitals can negatively impact both patients and doctors. It can make patients feel more anxious or depressive and can impair doctors' concentration or judgment, potentially leading to poor decision-making or performance. In China, an increasing number of outpatient operating rooms have emerged in recent years for the convenience of patients planning to undergo minor surgery. In this study, we aimed to investigate the impact of noise exposure in the outpatient operating room and ways to deal with it.
\end{abstract}

Methods: By monitoring noise at different locations in three hospitals, we analyzed the average noise exposure intensity affecting outpatient operative procedures. After noise monitoring, we made some constructive suggestions and other adjustments to reduce and lower the noise exposure in one outpatient operating room [the experimental operating room (EOR)] to observe the feasibility and effectiveness of noise control in and out of the outpatient operating room.

Results: Noise intensity in the outpatient operating room was significantly higher than that in the inpatient operating room $(68.3 \pm 14.7$ vs. $45.7 \pm 9.6, \mathrm{P}<0.05)$. After noise control, the noise intensity in the EOR decreased significantly $(74.5 \pm 16.6$ vs. $59.2 \pm 13.4, \mathrm{P}<0.05)$ but was still higher than that in the inpatient operating room $(59.2 \pm 13.4$ vs. $46.0 \pm 9.3, \mathrm{P}<0.05)$ of the same hospital. Further analysis revealed that noise affecting outpatient operating room mainly originates from vehicles outside, medical machines, ambulances, crowds in the outpatient main hall, and communication devices.

Conclusions: Noise exposure is a common and serious problem, but measures can be taken to deal with it effectively.

Keywords: Outpatient; operating room, noise exposure

Submitted Jan 05, 2020. Accepted for publication Mar 02, 2020.

doi: 10.21037 /gs.2020.04.09

View this article at: http://dx.doi.org/10.21037/gs.2020.04.09

\section{Introduction}

Hospitals are typically considered to be relatively quiet, peaceful places. However, with the development of urban areas and technology in recent times, hospitals have become noisier.

For patients' convenience, many hospitals are located in areas with heavy traffic, which goes hand in hand with a considerable amount of noise. The rapid progress of science and technology over recent decades has also seen the emergence of various instruments and equipment, which are often accompanied by varying degrees of noise. In addition, there are various other sounds stemming from sources in and around the hospital (e.g., babies crying, talking, and shouting). Of course, many of these noises are not pleasant and can affect people's moods, even causing different levels of psychological and physical damage $(1,2)$.

More and more studies are focusing on analyzing noise 
sources in hospital operating rooms and the associated impact on patients who undergo surgery and doctors who perform surgery, but these studies have so far mainly involved inpatient operating rooms. Usually, these operating rooms are reasonably designed in terms of building structure, floor location and being noise-free, and as such, the noise in an inpatient operating room is relatively less and lower in volume than that in an outpatient operating room. The majority of people in inpatient operating rooms, are doctors and nurses, who know the importance of keeping quiet, and studies have revealed that noise is mainly generated from medical instruments and equipment. Patients' relatives and friends are also often kept out of operating room and cannot be heard by the patients and doctors inside (3-5).

In recent years, outpatient operating rooms have developed rapidly, especially in hospitals which treat many patients each day. The outpatient building is often located at the forefront of the hospital, close to the main road, with a large number of people passing in, out, and around the building; the noise generated by these factors is often loud and continuous. Therefore, we conducted this study on the real situation of noise exposure in the outpatient operating room and explored methods to reduce the noise.

\section{Methods}

\section{Outpatient operating rooms}

We enrolled three different hospitals (hospital A, B, C) to monitor the noise exposure in their outpatient operating rooms. The inpatient operating rooms of these hospitals were also enrolled as controls. The outpatient operating room in hospital A (OOR-A) is located on the second floor of the outpatient building and is only 10 meters (direct distance) from the main road. This outpatient clinic provides medical services to about 5,000 patients a day. Outpatient operating room B (OOR-B) is located on the sixth floor of the clinic building, which is close to the crossroad of two main roads. The shortest direct distance from main road is 12 meters. Each day, services are provided to around 7,000 patients. Outpatient operating room C (OOR-C) is located on the first floor of the outpatient building, and the direct distance from the main road is 18 meters. This clinic treats about 4,000 patients a day. As a control, the inpatient operating rooms were all located more than 50 meters from the main road. This study was approved by ethics committee at each of the hospitals.

\section{Noise monitoring}

\section{Monitoring points}

point a was in the operating room, near the position of the patient's head during surgery, but not affecting the operation procedure; point $\mathrm{b}$ was in the waiting room outside the operating room; point c was in the medical staff's rest area; and point $\mathrm{d}$ was in the center of the outpatient hall.

\section{Noise detection}

Noise was detected by NJ-2 sound meter (Jiangxi Hongsheng Equipment Factory), once an hour, for 10 hours a day ( 8 am to $6 \mathrm{pm})$, for 3 days.

\section{Noise classification}

The results were graded using international $\mathrm{dB}-\mathrm{A}$ unit: the threshold to be heard is $10 \mathrm{~dB} ; 10-40 \mathrm{~dB}$ is relatively quiet; $40-80 \mathrm{~dB}$ is medium-level sound; and $80-100 \mathrm{~dB}$ is very loud.

\section{Noise reduction}

OOR-A was transformed into a relatively independent and closed area: the windows were remodeled and soundproof glass was installed; the sound intensity of equipment and equipment alarms was adjusted to a relatively lower level and any unnecessary alarms were turned off; and warnings were added to impose a greater level of noise management. After noise control was implemented, the outpatient operating room and inpatient operating room of hospital A were monitored again according to the aforementioned method.

\section{Statistical analysis}

Continuous variables were expressed as mean \pm standard deviation and compared using an unpaired, two-sided Student's $t$-test when normal distribution and equal dispersion were confirmed. The Mann-Whitney $U$ test and the Wilcoxon's signed-rank test were used when the variance was unequal. Categorical variables were expressed as percentages (\%) and compared using chi-squared analysis or Fisher's exact test if necessary. A P value $<0.05$ was considered statistically significant. All statistical analyses were performed using SPSS (version 17.0 for Windows, SPSS, Inc., IL, USA). 
Table 1 Comparison of noise intensity at each monitoring point

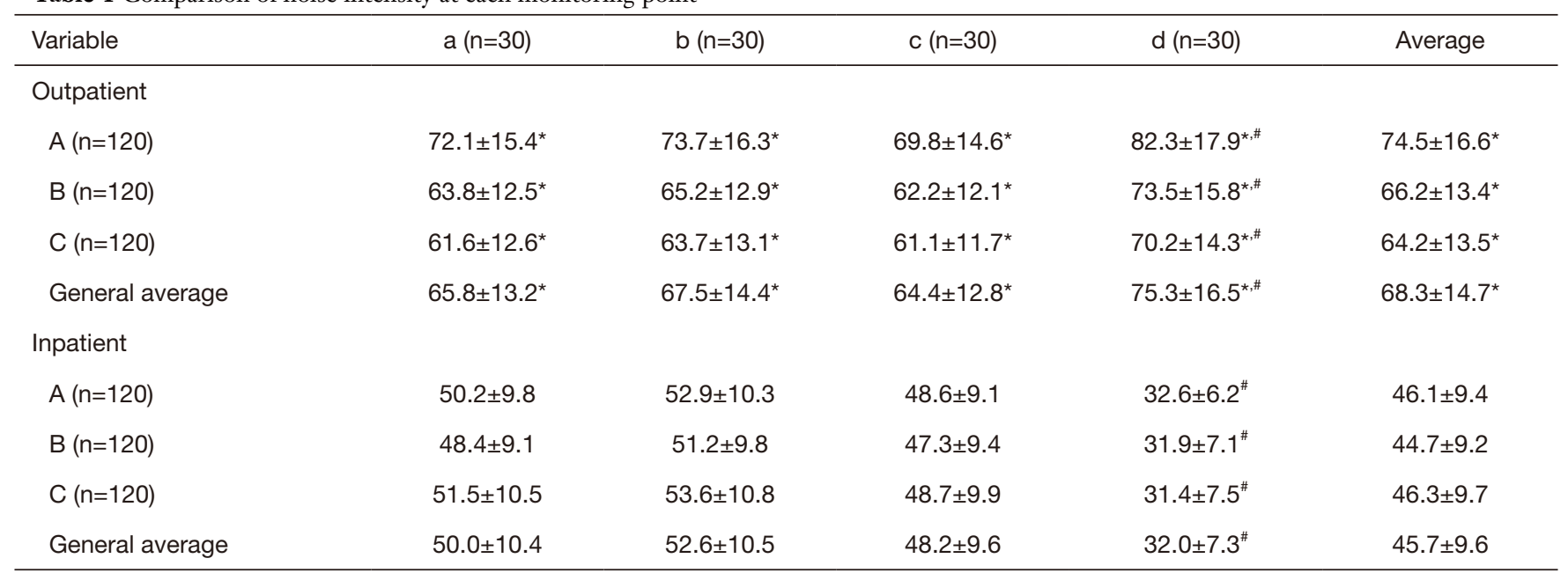

Compared with the results of simultaneous monitoring in the inpatient operating room, ${ }^{*}, \mathrm{P}<0.05$; compared with other monitoring points, \#, $\mathrm{P}<0.05$.

Table 2 Comparison of noise in the outpatient operating room before and after noise control in hospital A

\begin{tabular}{|c|c|c|c|c|c|}
\hline Variable & $a(n=30)$ & $b(n=30)$ & $c(n=30)$ & $d(n=30)$ & Average \\
\hline Before & $72.1 \pm 15.4$ & $73.7 \pm 16.3$ & $69.8 \pm 14.6$ & $82.3 \pm 17.9$ & $74.5 \pm 16.6$ \\
\hline After & $55.8 \pm 12.5^{\star \text {,\# }}$ & $57.2 \pm 12.9^{\text {*,\# }}$ & $55.2 \pm 12.1^{\text {*,\# }}$ & $66.5 \pm 15.8^{\text {*,\# }}$ & $59.2 \pm 13.4^{\text {*, th }}$ \\
\hline \multicolumn{6}{|l|}{ Inpatient } \\
\hline After & $50.6 \pm 10.5$ & $52.5 \pm 10.7$ & $47.9 \pm 9.8$ & $32.9 \pm 7.1$ & $46.0 \pm 9.3$ \\
\hline
\end{tabular}

Compared with the noise intensity before adjustment, *, $\mathrm{P}<0.05$; compared with the results from the same period from monitoring in the inpatient operating room of the same hospital, ", $\mathrm{P}<0.05$.

\section{Results}

\section{Comparison of noise in the outpatient and inpatient operating rooms}

After continuous monitoring for 3 days, 30 noise intensity values were acquired at each point. The average noise intensity of the outpatient operating room was found to be significantly higher than that of the inpatient operating room $(68.3 \pm 14.7$ vs. $45.7 \pm 9.6, \mathrm{P}<0.05)$. Of the three outpatient operating rooms, operating room A had the highest average noise intensity $(\mathrm{P}<0.05)$, followed by $\mathrm{B}$, and $\mathrm{C}$ had the lowest. There was no significant difference between $\mathrm{B}$ and $\mathrm{C}(\mathrm{P}>0.05)$. In relation to the four monitoring points located in various parts of the outpatient department, the average noise intensity at point $d$ was the highest $(\mathrm{P}<0.05)$, and there was no statistical difference between the other three points $(\mathrm{P}>0.05)$. Regarding the four monitoring points in the inpatient department, $a, b$, and $c$ had no statistical difference of noise intensity, and the noise intensity at point $\mathrm{d}$ was the lowest $(\mathrm{P}<0.05)$. Details are listed in Table 1.

\section{Changes in the noise intensity of the outpatient operating room after noise control}

We found that noise intensity in the outpatient operating room decreased significantly after constructive adjustment $(74.5 \pm 16.6$ vs. $59.2 \pm 13.4, \mathrm{P}<0.05)$, but it was still higher than the monitoring results of the in-patient operating room during the same period (no further improvements were made to the inpatient operating room). Details are listed in Table 2. 


\section{Analysis of noise sources influencing the outpatient operating room}

We used instruments to detect noise in and around the outpatient building and found the following sources to be the main contributors to noise in the outpatient operating room: noise from nearby roads, especially those with heavy traffic; construction noise from nearby building sites; noise from instruments and equipment; ambulance sirens; and sounds from patients and communication equipment ringtones. The loudest noise from outside the outpatient operating room in hospital A measured $92 \mathrm{~dB}$. The loudest noise measured at the outpatient room in hospital B, which was directly above the emergency department, was $89 \mathrm{~dB}$. In both cases, the noise came from ambulance sirens or other vehicles. The highest intensity of noise measured in the center of the outpatient hall was $81 \mathrm{~dB}$, and noise generated by equipment and instruments in the operating room reached $88 \mathrm{~dB}$.

\section{Discussion}

Noise pollution is well known to have adverse effects on human physiological and psychological health. Long-term noise exposure could affect the sympathetic nervous system, increase blood pressure, or result in inattention, poor sleep, bad memory, and impairment of reaction ability (6-8). Short-term noise exposure can cause transient stress states, leading to stress and anxiety $(9,10)$.

As places of healing, hospitals have high requirements for noise control. After more than 100 years of development, noise control inside hospitals, especially inpatient buildings, is extremely effective. However, with advancements in equipment such as ventilators and monitors came new sources of noise, and this is continuing to increase. Devices work with different levels of alarm sounds, and if the sounds are sharp and harsh, this can easily lead to stress among medical staff and patients and their families $(11,12)$.

In recent years, many noise-proof techniques have been used in inpatient operating rooms, and noise level has been greatly reduced $(13,14)$. However, as outpatient operating rooms have emerged only in recent years, there are few related studies that have analyzed the actual situation and methods to deal with the noise. At the same time, most outpatient operating rooms are located in outpatient buildings, which are usually located very close to the main road and the emergency department, both of which are noisy. Therefore, we conducted noise monitoring in the outpatient operating rooms of three different hospitals and implemented noise control in one of them.

The reason for the noise in the outpatient operating room being significantly higher than that in the inpatient operating room comes mainly as a result of the difference in geographical location between these two kinds of operating rooms. Most inpatient buildings are located faraway from main road to avoid loud noise, keeping wards quiet. Inpatient operating rooms have also been designed with soundproof materials and techniques. However, in most hospitals, outpatient operating rooms have only come to exist in recent years. Outpatient operating rooms are usually close to the main road, where a lot of vehicles come and go.

In our study, the main source of noise affecting the outpatient operating rooms was road vehicle noise, which is unpredictable. The second main source was the sound of instruments and equipment in the operating room. However, we found that the entire outpatient environment is exposed to loud noise, which inevitably affects the entire patient experience.

When a patient arrives at hospital with discomfort, noise around the outpatient department could cause anxiety, nervousness, and irritability. As they wait for surgery, the patient could encounter continuous noise, increasing their anxiety, tension, or stress. For medical staff, noiseespecially unexpected noise-can make decision-making or concentrating on a procedure difficult (15). All of these adverse effects could result in the failure of surgery and be very harmful to patients. Therefore, from the perspective of full-process management, while outpatient operating rooms are being developed, noise control should be considered, to try and create a quiet environment for outpatient operations. With these changes, we will ensure that patients are treated in a quiet and comfortable environment.

According to the results of our noise monitoring, we performed noise control in hospital A to reduce noise inside and outside the outpatient operating room. These specific measures took into account the entire process of medical services. Outside the hospital, we set up warnings instructing drivers to avoid unnecessary use of their vehicle horns. In-hospital warnings were also put up, especially in the main hall of the outpatient building and waiting area, reminding people to not speak loudly and to switch their mobile phone to vibration mode. The operating room was reinforced with soundproof materials and techniques. Alarm volume was turned lower or canceled if not essential. Soft music was broadcast in the waiting area outside the operating room to relax patients. Starting from the entrance 
of the outpatient building, noise control was implemented throughout the building.

\section{Conclusions}

In our study, we found that the noise in the outpatient operating room was louder than that in the inpatient operating room but could be reduced effectively with appropriate measures. However, even with considerable improvements in soundproofing, the noise in the outpatient operating room was still louder than that in the inpatient operating room.

\section{Acknowledgments}

Funding: None.

\section{Footnote}

Conflicts of Interest: All authors have completed the ICMJE uniform disclosure form (available at http://dx.doi. org/10.21037/gs.2020.04.09). The authors have no conflicts of interest to declare.

Ethical Statement: The authors are accountable for all aspects of the work in ensuring that questions related to the accuracy or integrity of any part of the work are appropriately investigated and resolved. This study was approved by ethics committee at each of the hospitals.

Open Access Statement: This is an Open Access article distributed in accordance with the Creative Commons Attribution-NonCommercial-NoDerivs 4.0 International License (CC BY-NC-ND 4.0), which permits the noncommercial replication and distribution of the article with the strict proviso that no changes or edits are made and the original work is properly cited (including links to both the formal publication through the relevant DOI and the license). See: https://creativecommons.org/licenses/by-nc-nd/4.0/.

\section{References}

1. Basner M, Babisch W, Davis A, et al. Auditory and non-auditory effects of noise on health. Lancet 2014;383:1325-32.

2. Wright BA, Peters ER, Ettinger U, et al. Moderators of noise-induced cognitive change in healthy adults. Noise Health 2016;18:117-32.
3. Cheriyan S, Mowery H, Ruckle D, et al. The Impact of Operating Room Noise Upon Communication During Percutaneous Nephrostolithotomy. J Endourol 2016;30:1062-6.

4. Keller S, Tschan F, Beldi G, et al. Noise peaks influence communication in the operating room. An observational study. Ergonomics 2016;59:1541-52.

5. Way TJ, Long A, Weihing J, et al. Effect of noise on auditory processing in the operating room. J Am Coll Surg 2013;216:933-8.

6. Kim J, Lee W, Won JU, et al. The relationship between occupational noise and vibration exposure and headache/ eyestrain, based on the fourth Korean Working Condition Survey (KWCS). PLoS One 2017;12:e0177846.

7. Chen S, Ni Y, Zhang L, et al. Noise exposure in occupational setting associated with elevated blood pressure in China. BMC Public Health 2017;17:107.

8. Lee S, LeeW, Roh J, et al. Symptoms of Nervous System Related Disorders Among Workers Exposed to Occupational Noise and Vibration in Korea. J Occup Environ Med 2017;59:191-7.

9. Pouryaghoub G, Mehrdad R, Valipouri A. Effect of acute noise exposure on salivary cortisol: a randomized controlled trial. Acta Med Iran 2016;54:657-61.

10. Gannouni N, Mhamdi A, El May M, et al. Morphological changes of adrenal gland and heart tissue after varying duration of noise exposure in adult rat. Noise Health 2014;16:416-21.

11. Katz JD. Noise in the Operating Room. Anesthesiology 2014;121:894-8.

12. Sandra K, Franziska T, Norbert KS, et al. Noise in the Operating Room Distracts Members of the Surgical Team. An Observational Study. World J Surg 2018;42:3880-7.

13. Dorthe H, Helle TM, Palle T, et al. Patients' Perception of Noise in the Operating Room-A Descriptive and Analytic Cross-Sectional Study. J Perianesth Nurs 2014;29:410-7.

14. Wang XX, Zeng L, Li G, et al. A cross-sectional study in a tertiary care hospital in China: noise or silence in the operating room. BMJ Open 2017;7:e016316.

15. Keller S, Tschan F, Beldi G, et al. Noise peaks influence communication in the operating room. An observational study. Ergonomics 2016;59:1541-52.

Cite this article as: Liu M, Yi C, Yin F, Dai Y. Noise in the outpatient operating room. Gland Surg 2020;9(2):380-384. doi: 10.21037/gs.2020.04.09 